luri S. Bessa*, Márcia M. Takahashi, Kamilla L. Vasconcelos, and Liedi L. B. Bernucci

\title{
Characterization of neat and modified asphalt binders and mixtures in relation to permanent deformation
}

https://doi.org/10.1515/secm-2019-0022

Received December 11, 2018; accepted March 1, 2019

\begin{abstract}
The addition of polymers on asphalt binders aims to enhance their performance, especially at high temperatures, which correspond to rutting resistance. The $\mathrm{Su}$ perpave rutting parameter $\left(\left|\mathrm{G}^{\star}\right| / \sin \delta\right)$ has been considered to be inadequate to characterize the performance of modified materials, therefore the Multiple Stress Creep and Recovery (MSCR) test was developed, providing the parameter non-recoverable compliance (Jnr). This research has the main objective of correlating asphalt binders performance-based characterization with rutting resistance of asphalt mixtures, and presents results obtained for one conventional (50/70 penetration grade) and two modified asphalt binders (2.1\% RET and 1.9\% RET) regarding their rheological characteristics. With the use of the dynamic shear rheometer (DSR), master curves and MSCR results were obtained for the three binders. In addition, permanent deformation tests were performed on the asphalt mixtures by means of laboratory traffic simulation. The rutting characterization indicated higher permanent deformation resistance for the modified binders for the asphalt binder and the asphalt mixture testing. The main conclusions were that the use of modified binder reduced in approximately 50\% the Jnr values and the rut depth; also, the asphalt binders' characteristics were able to predict the asphalt mixtures rutting resistance.
\end{abstract}

Keywords: asphalt binder; asphalt mixture; permanent deformation; MSCR test; traffic simulation

\footnotetext{
*Corresponding Author: Iuri S. Bessa: Universidade de São Paulo (USP) Escola Politécnica Laboratório de Tecnologia de Pavimentação (LTP) Av. Prof. Almeida Prado, Travessa 2, No. 83 Cidade Universitária, São Paulo, SP, Brazil Zip Code: 05508-070, E-mail: iuribessa@usp.br

Márcia M. Takahashi: Universidade de São Paulo (USP) Escola Politécnica Laboratório de Tecnologia de Pavimentação (LTP) Av. Prof. Almeida Prado, Travessa 2, No. 83 Cidade Universitária, São Paulo, SP, Brazil Zip Code: 05508-070,

E-mail: marcia.takahashi@usp.br

Kamilla L. Vasconcelos: Universidade de São Paulo (USP) Escola Politécnica Laboratório de Tecnologia de Pavimentação (LTP) Av. Prof. Almeida Prado, Travessa 2, No. 83 Cidade Uni-
}

\section{Introduction}

The characterization of asphalt binders has been the scope of several researches especially in the past few years, due to the increasing use of modified materials in asphalt mixtures production. In the beginning of the 1990s, the Strategic Highway Research Program (SHRP) developed design projects and specifications to provide a new methodology for selection of asphalt binders in terms of their chemical and physical properties by addressing how these properties affect the performance of asphalt pavement structures. Before the development of SHRP, there were several empirical specification tests used for asphalt binder characterization but they were not capable of properly addressing performance-related properties of these materials and could not describe or predict in-field performance of asphalt pavements [1]. Also, the empirical characterization could not truly differentiate the behavior of modified asphalt binders from neat binders [2].

The original Superpave asphalt binder specification developed by the SHRP considers the parameter $\left|\mathrm{G}^{\star}\right| / \sin \delta$ to characterize and specify asphalt binders according to its rutting resistance at high pavement temperatures [1]. This parameter was introduced to the Superpave specifications based on good correlations with rut depth (after 1,000 cycles) values of seven different asphalt binders, including one modified material [1]. The loading frequency for the acquisition of the parameter is $10 \mathrm{rad} / \mathrm{s}$, which according to SHRP corresponds to $0.1 \mathrm{~s}$ in a sinusoidal loading and represents an average speed of a truck tire of $80 \mathrm{~km} / \mathrm{h}$ [3].

The current Superpave specification for asphalt binders is based on the Performance Grade (PG) of the material tested, which corresponds to the minimum and maximum temperatures to which the material can be submitted in the field. Currently, AASHTO M 320 (2015)

\footnotetext{
versitária, São Paulo, SP, Brazil Zip Code: 05508-070, E-mail: kamilla.vasconcelos@usp.br

Liedi L. B. Bernucci: Universidade de São Paulo (USP) Escola Politécnica Laboratório de Tecnologia de Pavimentação (LTP) Av. Prof. Almeida Prado, Travessa 2, No. 83 Cidade Universitária, São Paulo, SP, Brazil Zip Code: 05508-070, E-mail: liedi@usp.br
} 
requires a minimum value of $1.00 \mathrm{kPa}$ for $\left|\mathrm{G}^{\star}\right| / \sin \delta$ for unaged specimens at the average 7-day high maximum pavement design temperature. For short-term aged specimens (rolling thin film oven test, RTFOT, ASTM D 2872, 2012), there are two standards that can be taken into consideration. For the conventional characterization (AASHTO M 320, 2015), the Superpave parameter $\left|\mathrm{G}^{\star}\right| / \sin \delta$ should be a minimum value of $2.2 \mathrm{kPa}$. The other standard considered for PG purposes (AASHTO M $332,2014)$ requires maximum values for the parameter $\mathrm{Jnr}$ (non-recoverable creep compliance) and for \%R (percent recovery), which depend on the traffic loading to which the asphalt binder will be designed. This parameter is obtained by means of the multiple stress creep and recovery (MSCR) test, which was developed by D'Angelo et al. [4] and has been widely investigated by several researchers in the past years in terms of testing geometry, number of cycles, time of creep, time of recovery, stress sensitivity parameter, and loading magnitude.

Motamed and Bahia [5] concluded that changing the testing geometry to cone and plate might lead to true rutting behavior in comparison to parallel plate. Golalipour et al. [6] suggested the increase of number of cycles per stress to 20 , because 10 cycles might not be sufficient to reach a steady-state creep behavior for modified asphalt binders. Kataware and Singh [7] tested different times of creep and recovery and concluded that increasing the creep period has more effect than increasing the recovery period. Merusi [8] found similar results for most of the materials tested. Domingos and Faxina [9] performed the MSCR test with creep and recovery times of 2 and $18 \mathrm{~s}$, instead of the conventional $1 / 9 \mathrm{~s}$ and found lower rutting resistance, which also led to changing the acceptable traffic level for some asphalt binders tested. Elnasri et al. [10] consider that there should be a 5 -minute rest period between the different stress levels loadings in order to provide a proper recovery of the asphalt binder during the test.

In terms of stress sensitivity, Stempihar et al. [11] considered that the current parameter used in the MSCR test penalizes asphalt binders with low values of Jnr; therefore, these authors proposed an alternate parameter that could represent this characteristic more properly. Delgadillo et al. [12] concluded that different temperatures lead to different levels of stress sensitivity. In terms of stress levels, D’Angelo [13] proposed correlations between rutting and Jnr values measured at different loading magnitudes and concluded that at $3.2 \mathrm{kPa}$ the results can be well-correlated to field. Golalipour [14] proposed higher stress levels in order to differentiate better the behavior of asphalt binders with different polymer-modification. Wasage et al. [15] found that increasing the stress levels up to $10,000 \mathrm{~Pa}$ might lead to changes in Jnr values only for modified asphalt binders, while Saboo and Jumar [16] found that modified materials have different sensitivity to the stress levels applied depending on the type of polymer used for modification.

The objective of the present research paper is to compare the rheological characterization of neat and modified asphalt binders with the rutting behavior of asphalt mixtures constituted by these materials. For the binder characterization, the linear viscoelastic properties, the Superpave rutting parameter $\left(\left|\mathrm{G}^{\star}\right| / \sin \delta\right)$, and the MSCR test results (Jnr and \%R) were obtained. Furthermore, asphalt mixtures specimens were produced with the same asphalt binders previously tested, and the wheel-tracking test was performed to analyze rut depth.

\section{Literature Review}

The selection of the type and quality of an asphalt binder to be used in the design of highway structures depends mostly on the pavement temperature and traffic level. Despite having a lower effect on the rutting resistance of asphalt mixtures in comparison to the aggregates, good quality asphalt binders enhance the performance of asphalt mixtures, especially for high traffic highways [17-25].

The use of neat asphalt binders has been an issue for the pavement engineering market due to the constant increase of traffic levels, the occurrence of larger and heavier trucks, and the increasing tire pressure, all of which decrease the service life of asphalt pavement surface mixtures. The performance of asphalt pavements is also greatly affected by the temperature in which they are constructed and which it operates, due to the asphalt binders' viscoelastic properties. The viscosity can be affected by high temperatures, resulting in a weaker material, which negatively affects the resistance to permanent deformation.

The modification of asphalt binder [18, 26-31] has become one of the best solutions to enhance the rheological characteristics of asphalt mixtures, especially for high temperature environments where rutting resistance is more affected. Polymer modification tends to reduce temperature susceptibility. It also increases the stiffness at high temperatures and decreases stiffness at low temperatures, reducing rutting and fatigue cracking, respectively [32]. The modification might also increase the interface interaction between the binder and mineral filler, which might affect the asphalt mixtures performance in terms of rutting resistance. Guo and Tan [33] tested four 
types of mineral fillers and two asphalt binders and concluded that the binder-filler interaction degree increases with higher surface area values and more polar components of the asphalt binder, enhancing the rutting behavior of asphalt mixtures.

There are several types of polymers that can be used for asphalt binder modification, and they can be divided into three main categories [34]: thermoplastic elastomers, plastomers, and reactive polymers. Despite all providing better resistance to the distresses found in asphalt pavements, there are differences among them. Reactive polymers, e.g., Evaloy, tend to have better storage stability in comparison to the other modifiers, e.g., SBS [35, 36]. Bulatovic et al. [37] stated that this occurs due to the formation of chemical bond between the polymer and the asphaltenes from the asphalt binder, which prevents phase separation.

Yildirim [38] did a literature review on the use of polymer-modified asphalt binders and concluded that different types of asphalt modification might lead to different responses to the main distresses. SBS-modified (nonreactive) asphalt binders tend to perform better than neat binders especially in low temperatures, while Elvaloymodified (reactive) asphalt binders increase the performance in high temperatures. Wang et al. [39] studied one neat and one SBS-modified asphalt binder with $4.5 \%$ polymer in terms of the MSCR test using the same temperature $\left(60^{\circ} \mathrm{C}\right)$ for both materials, and obtained a Jnr value lower than $50 \%$ for the SBS-modified material in comparison to the non-modified binder. Huang and Tang [40] characterized asphalt binders with different contents of SBS modifier. Jnr values decreased with the addition of SBS from 4.5 to $5.0 \%$ but did not change significantly when the content was increased to $5.5 \%$.

Blazejowski and Dolzycki [41] tested three different types of asphalt mixes - conventional asphalt concrete, high modulus asphalt concrete and stone mix asphalt (SMA) - for rutting resistance and compared the results to MSCR tests performed on the asphalt binders used in these mixtures. The correlation parameter $\left(R^{2}\right)$ was very high for the typical asphalt concrete, but low for the SMA, which might be explained by the great influence that the SMA's aggregate skeleton has on its rutting resistance [42]. The use of modified binders enhances the performance of asphalt mixtures by reducing the non-recoverable creep compliance values and increasing the percent recovery, which indicates improvement of high temperature stability and elasticity [40, 43].

Different tests and parameters have been used to obtain the rutting performance of asphalt mixtures through the characterization of the asphalt binder. Sybilski [44] used the concept of zero-shear viscosity of asphalt binders and found a fair correlation with results of. Wang and Zang [45] characterized neat and SBS-modified binders in terms of their non-recoverable response based on the parameter $\left|\mathrm{G}^{\star}\right| /[1-(1 / \tan \delta \sin \delta)]$ and concluded that this parameter predicts the rutting resistance better than the Superpave parameter $\left|\mathrm{G}^{\star}\right| / \sin \delta$.

The Federal Highway Administration (FHWA) performed accelerated tests in a real pavement section, compared the results to $\left|\mathrm{G}^{\star}\right| / \sin \delta$ values, and stated that the Superpave binder parameter is not able to reflect the effects that mix composition aggregate properties have on pavement performance [3]. In the past decade, D'Angelo [13] has proposed the MSCR test which uses the non-recoverable creep compliance (Jnr) and the percent recovery $(\% \mathrm{R})$ to evaluate asphalt binders' high temperature characteristics. It has been shown that this test provides better correlation to asphalt mixes' rutting performance than the traditional Superpave criteria.

Several authors have tried to correlate the rutting resistance of asphalt mixtures to the binder characterization data [46, 47]. Domingos et al. [48] found a good correlation between Jnr values and the rutting resistance of asphalt mixtures with varying asphalt binders but same aggregate structure of in terms of flow number (FN) results and also concluded that the ranking for these materials was the same for both scales. Differently, Bastos et al. [49] did not find a good correlation between these two parameters (Jnr and FN) for asphalt mixes with different aggregate gradation and internal structure. Jnr results also did not provide a good indicative of field performance in test sections studied by those authors.

\section{Laboratory Study}

\subsection{Materials and methods}

Three different asphalt cements (AC) were studied in this research: one neat 50/70 penetration grade asphalt binder (AC1); one polymer-modified asphalt binder with $2.1 \%$ of reactive elastomeric terpolymer Elvaloy ${ }^{\circledR}$ RET 4170 and $0.18 \%$ of polyphosphoric acid 116 (AC2); and another polymer-modified binder with $1.9 \%$ of terpolymer Elvaloy ${ }^{\circledR}$ RET 5170 and $0.18 \%$ of polyphosphoric acid 116 (AC3). Elvaloy ${ }^{\circledR}$ RET 4170 is an EnBAGMA (ethylene n-butyl acrylate/glycidyl methacrylate) terpolymer and Elvaloy ${ }^{\circledR}$ RET 5170 is an EEGMA (ethylene ester/glycidyl methacrylate) terpolymer. The two modified asphalt binders were produced after the modification of 
the same AC 50/70 studied in the present research. Rheological tests were performed on each material using the dynamic shear rheometer (DSR) and asphalt mixtures constituted by these three binders were compacted and tested in terms of rutting resistance on the Laboratoire Central des Ponts et Chaussées (LCPC) wheel-track testing equipment (EN 12697-22, 2003). The asphalt mixtures were composed by a blend of basaltic aggregates collected from a quarry in the State of São Paulo (Brazil) with the addition of hydrated lime $(1.5 \%)$ and $5.0 \%$ binder content. Figure 1 presents the aggregate size distribution of the three mixtures.

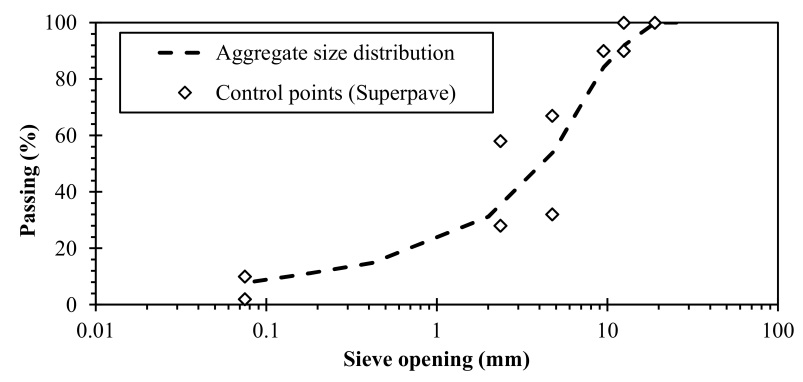

Figure 1: Aggregate size distribution

The characterization of the asphalt binders was done in order to provide the linear viscoelastic properties of the materials, which might be considered in design simulations for field performance prediction. The parameter Jnr was obtained by means of the MSCR test and it might be used for classification purposes and comparison between different materials, being also a powerful tool for rutting resistance prediction. In relation to the asphalt mixtures, the rutting resistance test normally validates an asphalt mixture to be used on an asphalt pavement roadway, by limiting the maximum percentage of deformation.

\subsection{Master curves}

The linear viscoelastic behavior of the asphalt materials indicates that their properties are dependent of loading frequency and temperature. Dynamic shear modulus $\left(\left|G^{\star}\right|\right)$ master curves of the three binders studied were plotted after the frequency-temperature sweep test. The tests were performed in three specimens for each binder, and they were all tested in their unaged and short-term aged conditions. The results were obtained after a frequency sweep (from 1 to $100 \mathrm{rad} / \mathrm{s}$ ) at different temperatures with $0.01 \%$ of strain amplitude. For the neat $\mathrm{AC}$, the temperature range was 46 to $76^{\circ} \mathrm{C}$ with increments of $6^{\circ} \mathrm{C}$. For the modified materials, the temperature of $82^{\circ} \mathrm{C}$ was also included, because these materials are capable of bearing higher temperatures than the neat binders. The master curves, using $52^{\circ} \mathrm{C}$ as reference, are presented in Figure 2. The authors observed that there was no significant variation among the different specimens (a total of two) of the same binder, indicating that the test did not present variability and that average values are a good representation of each binder tested.

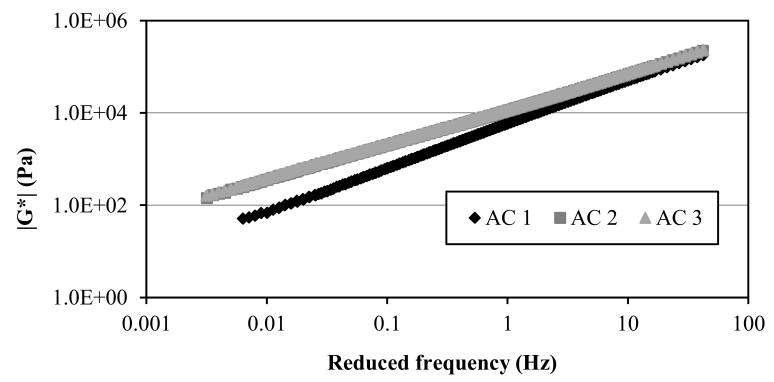

(a)

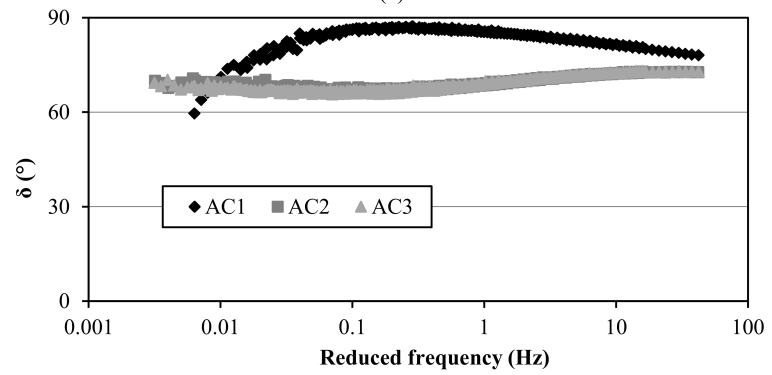

(b)

Figure 2: Master curves of: (a) dynamic shear modulus, $\left|G^{\star}\right|$ and (b) phase angle, $\delta$

The master curves are used to analyze the behavior of the materials studied at different temperatures and loading frequencies, which are related to the variation of field conditions. At low frequencies, equivalent to high temperatures for viscoelastic materials, the neat binder presented lower values of $\left|\mathrm{G}^{\star}\right|$ if compared to the values of the modified binders. This could be an indication that the modified materials are more likely to have better rutting resistance, because asphalt mixtures with high stiffness tend to resist more to traffic loads. At high frequencies, equivalent to low temperatures, the three materials had similar behavior. A comparison between the two modified binders shows that both materials behave almost equally in relation to $\left|G^{\star}\right|$ values at any frequency or any temperature conditions. Regarding the aging processes, the asphalt binders were also characterized in terms of their master curves after the use of RTFOT, and the results had the same trends as found for the unaged specimens. 


\subsection{Superpave rutting parameter $\left(\left|G^{*}\right| / \sin \delta\right)$}

The dynamic shear modulus $\left(\left|\mathrm{G}^{\star}\right|\right)$ and the phase angle $(\delta)$ of the binders were obtained through oscillatory tests run in the DSR according to ASTM D 7175 (2008). The tests were performed within a range of six different temperatures at the frequency of 10rad/s. Figure 3 presents the average results from three specimens of the Superpave parameter $\left|\mathrm{G}^{\star}\right| / \sin \delta$ for unaged and aged specimens (using RTFOT). The standard deviation values found between the three specimens for each temperature are plotted as error bars; however, these results are too low for most cases analyzed.

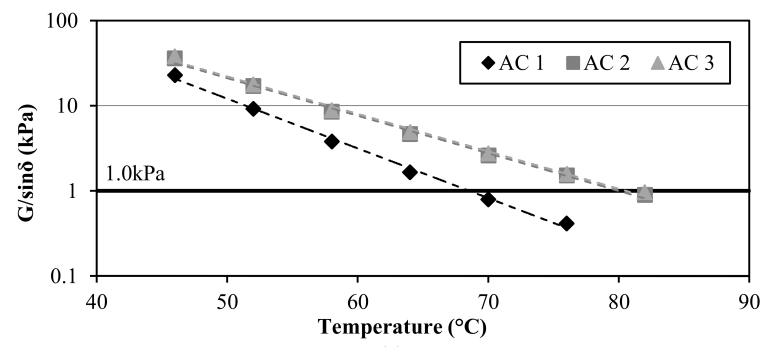

(a)

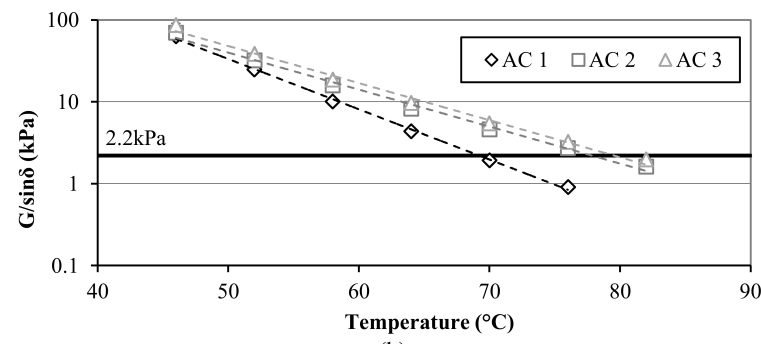

(b)

Figure 3: Superpave rutting parameter: (a) unaged and (b) RTFOTaged specimens

The modified binders have similar behavior in relation to the Superpave parameter analyzed at each testing temperature (at the frequency of $10 \mathrm{rad} / \mathrm{s}$ ). The neat binder presented lower values for both aging conditions. According to the Superpave specification, the minimum value for $\left|\mathrm{G}^{\star}\right| / \sin \delta$ should be $1.0 \mathrm{kPa}$ for unaged specimens, i.e., the neat binder might have an adequate behavior for permanent deformation until approximately $68^{\circ} \mathrm{C}$, while the modified binders might present a good resistance for this distress until approximately $80^{\circ} \mathrm{C}$. This indicates that the addition of reactive polymer enhanced the rutting resistance of both modified materials. For the aged samples, the traditional Superpave specification indicates a minimum value of $2.2 \mathrm{kPa}$. The neat binder presents a good behavior up to approximately $68^{\circ} \mathrm{C}$, with the modified binders up to $78^{\circ} \mathrm{C}$. In terms of thermal susceptibility, both modified binder presented smaller slopes as the testing temperature increased, indicating better behavior.

\subsection{Multiple stress creep and recovery (MSCR) test}

The MSCR test is included as part of the current Superpave specification (AASHTO M 332, 2014) and evaluates three major parameters: the percent recovery (\%R), the nonrecoverable creep compliance (Jnr), and the stress sensitivity ( $\left(\mathrm{nn}_{\text {diff }}\right)$ of the asphalt binders. The test consists in the application of creep and recovery periods for 1s and $9 \mathrm{~s}$, respectively, under two different stress levels (100 and 3,200 Pa). The AC specimens were tested after short-term aging (RTFOT), which is described by ASTM D 2872 (2012). Figure 4 presents the evolution of the strain for both stress levels during the test. Only one cycle of 10 s is represented in the graphs. The asphalt binders were tested at three temperatures $\left(64,70\right.$, and $\left.76^{\circ} \mathrm{C}\right)$, and the results for Jnr and $\mathrm{Jnr}_{\text {diff }}$ are shown in Figure 5 . Each result represents average values from three replicates, and the error bars correspond to one standard deviation from the mean value.
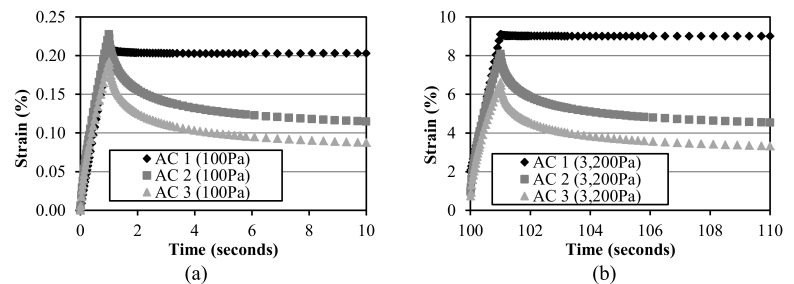

Figure 4: MSCR test results: (a) stress of $100 \mathrm{~Pa}$ and (b) stress of 3,200 Pa

As expected, the neat asphalt binder has higher values of Jnr for all the temperatures tested. The comparison between the two modified binders indicates that AC3 has a better rutting resistance, with Jnr values $25 \%$ lower than the ones obtained for the $\mathrm{AC} 2$ in all three temperatures. The Jnr ${ }_{\text {diff }}$ parameter was lower than the specification limit of $75 \%$, although this limit is under discussion on the technical community. Therefore, the materials studied could be used in asphalt mixtures regarding their stress sensitivity response.

The Jnr values for the different materials tested were chosen according to the maximum temperature obtained for the $\left|\mathrm{G}^{\star}\right| / \operatorname{sen} \delta$ results previously presented. Considering the temperature range provided by the PG specification, the respective values for the neat and the modified binders 


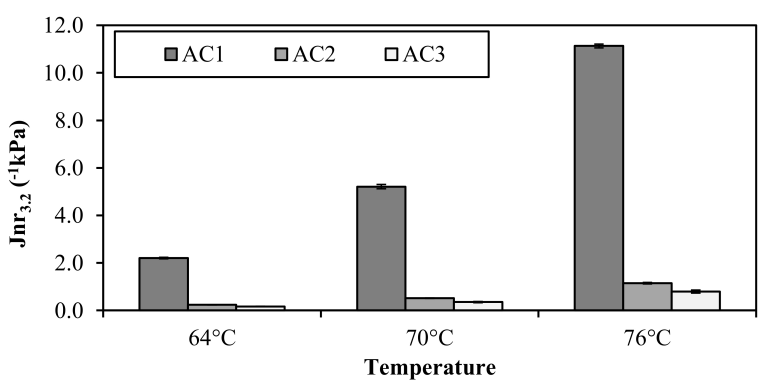

(a)

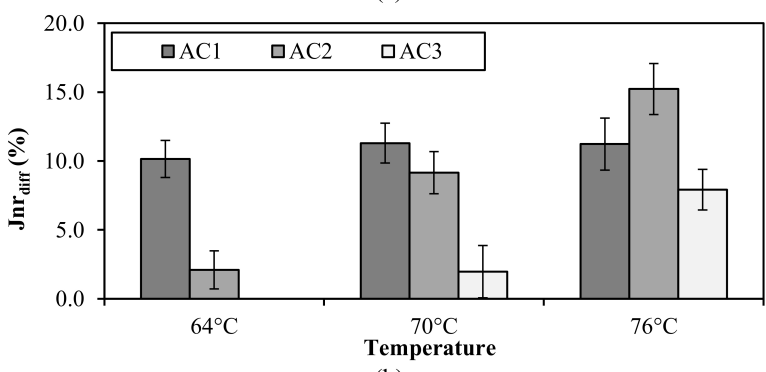

(b)

Figure 5: MSCR results at three different temperatures: (a) Jnr at $3.2 \mathrm{kPa}$ and (b) Jnr $\mathrm{Jiff}_{\text {f }}$

were 64 and $76^{\circ} \mathrm{C}$, respectively. Figure 6 presents the results (average values from three replicates at each condition) of Jnr and \%R for both stress levels applied during the test. In general, the $\% \mathrm{R}$ values have inversely proportional correlation with the Jnr values, i.e., as the $\%$ R increases, the Jnr decreases.

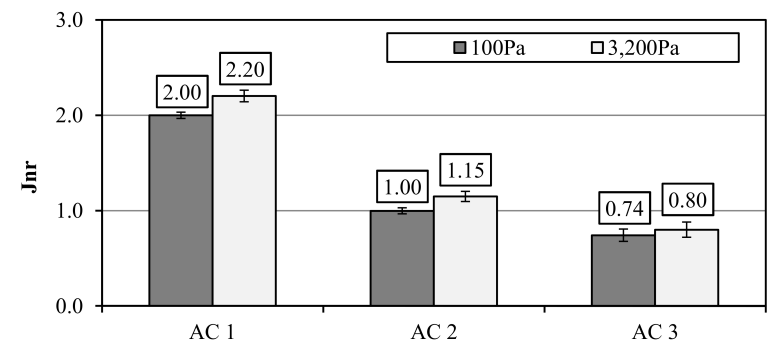

(a)

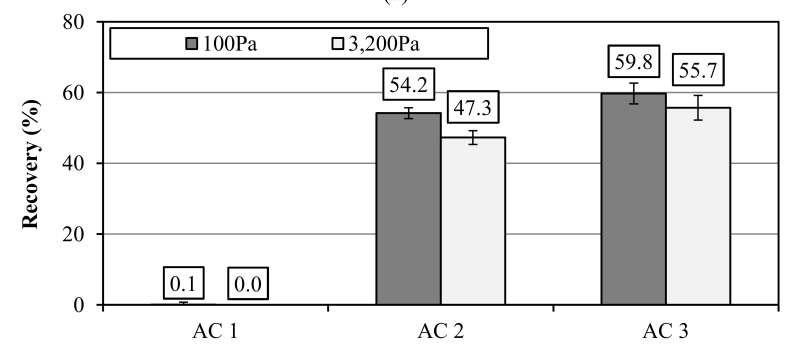

(b)

Figure 6: MSCR parameters at the PG temperatures: (a) Jnr and (b) $\% R$
The modification of the neat asphalt binder by reactive polymers decreased the values of Jnr in at least $50 \%$ of the original value (note that the testing temperature was different for the modified binders). Both modified binders presented similar results, but AC3 resulted in even lower values of non-recoverable compliance, which might indicate that this binder tends to have lower permanent deformation than AC2. A Student's t-test was done to evaluate if the Jnr values for the two modified asphalt binders were statistically similar, and the results obtained indicated that they are different (for a significance level of 5\%).

AASHTO M 332 (2014) provides a classification for the asphalt binders that includes the maximum limit values for Jnr according to different traffic loads: standard (S), heavy $(\mathrm{H})$, very heavy $(\mathrm{V})$ and extreme $(\mathrm{E})$, which is based on the number of AASHTO's accumulated equivalent single axle loads (ESALs) passing on the asphalt pavement during its life. Table 1 presents these limit values.

According to the specification, the neat binder could only be used for standard traffic (PG 64S-XX). As for the modified binders, AC2 could be used for heavy traffic (PG 76H-XX) and AC3 could be used for very heavy traffic (PG 76V-XX).

The MSCR test has some advantages in comparison to the traditional Superpave parameter $\left(\left|\mathrm{G}^{\star}\right| / \operatorname{sen} \delta\right)$. It provides the possibility of evaluating the dependency of polymer-modified binders in relation to stress levels, which is not possible with the traditional test because the latter is performed at the linear viscoelastic (LVE) region of the asphalt binder. Besides that, previous studies [4752] indicated that the Jnr value has provided better correlation to the permanent deformation of field and laboratory asphalt mixtures in relation to the correlations done with the parameter $\left|\mathrm{G}^{\star}\right| / \operatorname{sen} \delta$.

\subsection{Laboratory traffic simulation}

After the characterization of the asphalt binders, the present research performed a study on the asphalt mixtures. Two specimens of asphalt concrete slabs for each asphalt mixture was produced win the French roller compactor (EN 12697-33, 2003). These specimens were then subjected to the permanent deformation test performed by the French wheel tracking traffic simulator (EN 12697-22, 2003). The mixing and compaction temperatures were 153 and $140^{\circ} \mathrm{C}$ for the mixture constituted by the neat binder, respectively; and 165 and $155^{\circ} \mathrm{C}$ for the modified binders, respectively. For the preparation of the slabs, a pugmill mixer was used to blend the materials, simulating filed 
Table 1: Traffic level according to Jnr (AASHTO M 332, 2014)

\begin{tabular}{cccc}
\hline Traffic level & $\begin{array}{c}\text { Number of ESALs and } \\
\text { traffic speed }\end{array}$ & $\begin{array}{c}\text { Maximum value of Jnr at } \\
\mathbf{3 . 2} \mathbf{k P a}\left(\mathbf{k P a}^{-1}\right)\end{array}$ & $\begin{array}{c}\text { Maximum value of } \\
\mathbf{J n r} \text { diff }(\%)\end{array}$ \\
\hline Standard $(\mathrm{S})$ & $<10 \times 10^{6}$ and $>70 \mathrm{~km} / \mathrm{h}$ & 4.5 & 75.0 \\
\hline Heavy $(\mathrm{H})$ & $\begin{array}{c}10 \times 10^{6}-30 \times 10^{6} \text { or } \\
20-70 \mathrm{~km} / \mathrm{h}\end{array}$ & 2.0 & 75.0 \\
\hline Very heavy $(\mathrm{V})$ & $>30 \times 10^{6} \mathrm{or}<20 \mathrm{~km} / \mathrm{h}$ & 1.0 & 75.0 \\
\hline Extreme $(\mathrm{E})$ & $>30 \times 10^{6}$ and $<20 \mathrm{~km} / \mathrm{h}$ & 0.5 & 75.0 \\
\hline
\end{tabular}

mixing conditions. After the mixing process, the asphalt mixes were kept in the oven for a period of $2 \mathrm{~h}$ at the compaction temperature to simulate the time between the mixing and placement of the mixtures in the field.

The slab specimens were prepared by the LCPC French slab compactor, in which the asphalt mix was compacted by roller compactor (similar to real field compaction) after a sequence of passing of standard tires with pressure varying from 0.3 to $0.6 \mathrm{MPa}$. The rutting resistance test was performed by the LCPC traffic simulator. For each mix, two $50 \mathrm{~mm}$-thick, $180 \mathrm{~mm}$-width and $500 \mathrm{~mm}$-length slab specimens were tested. The test was done at the temperature of $60^{\circ} \mathrm{C}$ and consists in applying a load of $5 \mathrm{kN}$ to each sample at a frequency of $1.0 \mathrm{~Hz}$. After 100, 300, 1,000, 3,000, 10,000 and 30,000 cycles, the rut depth was measured in each sample. In terms of recommended limits for rutting, in Brazil, a maximum value of $5 \%$ of rutting after 30,000 cycles is normally considered for use of the asphalt mixture in heavy traffic roads [53]. Figure 7 presents the average results obtained for all the three mixtures produced in terms of rut depth. For each mixture, two slab specimens were submitted to traffic simulation.

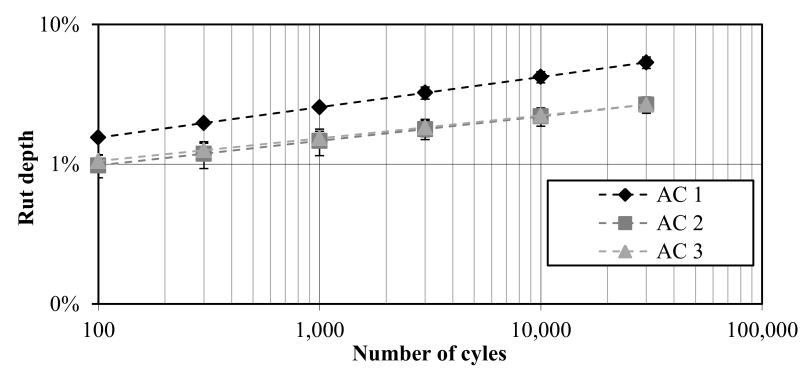

Figure 7: Rut depth results

The conventional mixture produced by the neat binder had the worst behavior in terms of rutting $(5.3 \%$ after 30,000 cycles). In relation to the mixtures using the modified binders, the rut depth values were very similar $(2.7 \%$ at the end of the test), indicating the both mixtures have the

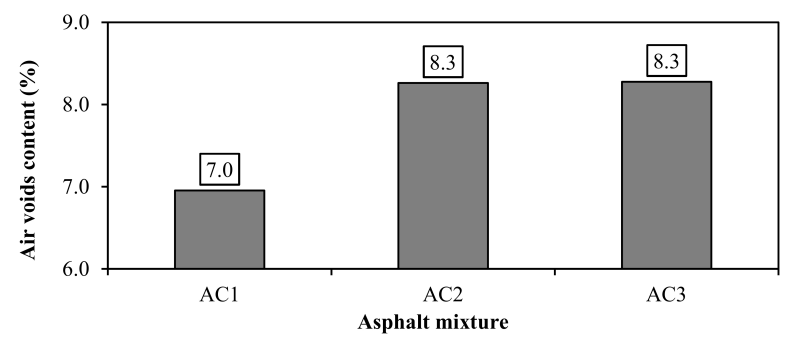

Figure 8: Air voids contents

same permanent deformation resistance behavior. It is important to note that the mix design of all three mixes was the same (same gradation and same AC content). The air voids content of the asphalt mixtures were measured from one specimen of each asphalt mixture (Figure 8) to evaluate the influence of this parameter on the results of rut depth, considering that the same binder content was used for the three mixtures. The results show that the modified asphalt mixtures performed were not influenced by their air voids content, but these values were very similar for both those mixtures. The unmodified asphalt mixture presented higher values of rut depth despite having lower air voids content.

Correlations between rut depth and $\left|\mathrm{G}^{\star}\right| / \sin \delta$ values (Figure 9a), and rut depth and Jnr values (Figure 9b) are provided. There is good linear correlation with the latter ( $R^{2}$ value of approximately 0.95), although the authors are aware that more data should be provided in further research. One of the main reasons for the good indication of rutting resistance provided by the asphalt binders might be explained by the changes that normally occur after the polymer-modification. The asphalt binders tend to have higher stiffness at high temperatures and tend to be more elastic. These aspects can be noticed by the master curves of each material. It is important to note that the aggregates' properties and size distribution were the same for the three mixtures evaluated in the present study, but other gradations and other aggregate sources could lead to different results and lower values of $\mathrm{R}^{2}$. Despite result- 


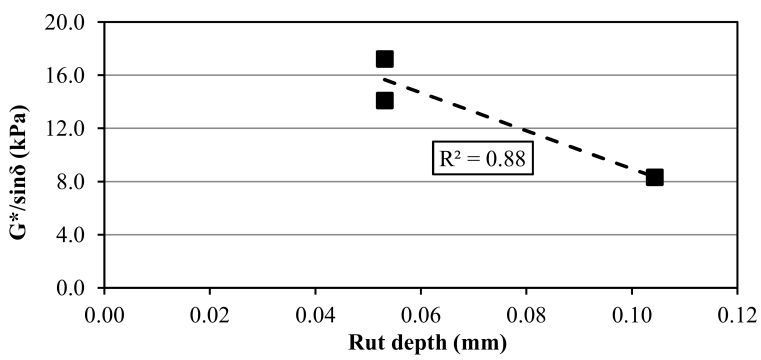

(a)

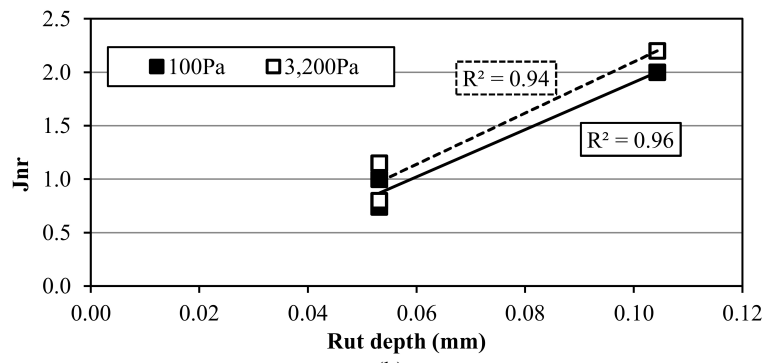

(b)

Figure 9: Comparison of rut depth with: (a) $\left|\mathrm{G}^{\star}\right| / \sin \delta$ and (b) Jnr

ing in a fair correlation, the Superpave parameter should be avoided because it does not address well the modified asphalt binders' performance with respect to permanent deformation. The higher values of $\left|\mathrm{G}^{\star}\right| / \sin \delta$ for the AC3 would indicate better resistance to permanent deformation, but that was not observed in the wheel-track simulation test, which resulted in almost identical rut depth values for the two modified binders.

\section{Summary and Conclusions}

The present research evaluated three different asphalt binders in relation to their linear viscoelastic and permanent deformation properties: 50/70 neat binder (AC1), one polymer-modified binder with $2.1 \%$ of RET 4170 and $0.18 \%$ of PPA 116 (AC2), and another polymer-modified binder with $1.9 \%$ of RET 5170 and $0.18 \%$ of PPA 116 (AC3). The two modified binders were produced with the same AC 50/70 base. Rheological tests were performed in order to obtain the Superpave traditional parameter of $\left|\mathrm{G}^{\star}\right| / \sin \delta$ normally used to characterize binders in relation to rutting resistance and master curves after temperature and frequency sweeps. After that, the MSCR test was performed to obtain the non-recoverable creep compliance and the percent strain recovery of the materials; also, the wheeltracking test was performed in asphalt mixtures constituted by the same binder to measure their rutting resis- tance. Some of the conclusions obtained after the studies are:

- The modification of asphalt binders with reactive polymer tends to enhance their performance in relation to permanent deformation; the values of $\left|\mathrm{G}^{\star}\right| / \sin \delta$ before and after the aging process are higher for the modified materials, especially with increasing temperature;

- The polymer-modified binders are less susceptible to temperature changes; with the increase of temperature, the neat binder tends to lose its rigidity more rapidly;

- The modified binders can generally be used in heavy or very heavy traffic levels, according to Jnr values; on the other hand, the neat binder tested can only be used in standard traffic level;

- Despite being classified in different traffic grades, the two modified asphalt binders resulted in similar rut depth values;

- There was a good correlation between rut depth values and non-recoverable creep compliance values, which show that the MSCR test can be a good indication of permanent deformation resistance of asphalt mixtures.

Further work should be done to add more information to the data presented in this research. The present research tested asphalt mixtures with the same binder content and aggregate skeleton, thus these properties did not influence the results provided; however, it is well-known that these characteristics, especially the aggregate particles behavior, have major effects on the rutting resistance of asphalt mixtures. Other types of asphalt mixtures, with different gradations, should also be studied in order to better describe the correlations between the traffic simulator test and the MSCR results. The fatigue resistance characterization should also be characterized in order to compare the binder with asphalt mixtures results.

Acknowledgments The authors would like to acknowledge DuPont Brasil for providing the materials used in this research. CAPES and CNPq are also acknowledged for the financial support given to the authors.

\section{References}

[1] Petersen, JC, Robertson RE, Branthaver JF, Harnsberger PM, Duvall JJ, Kim SS, Anderson DA, Christiansen DW, Bahia HU. Binder Characterization and Evaluation - Volume 1. Report SHRP-A367, Strategic Highway Research Program, National Research Council, 1994. 
[2] Gershkoff DR, Carswell J, Nicholls JC. Rheological Properties of Polymer-Modified Binders for Use in Rolled Asphalt Wearing Course, Thomas Telford Ltd.: London, UK, 1997.

[3] Stuart KD, Mogawer WS, Romero P. Validation of Asphalt Binder and Mixture Tests that Measure Rutting Susceptibility Using the Accelerated Loading Facility. Final Report, FHWA-RD-99. 204, Federal Highway Administration, U.S. Department of Transportation, 1999.

[4] D’Angelo J, Kluttz R, Dongré R, Stephens K, Zanzotto L. J. Assoc. Asphalt Paving Technol. 2007, 76, 123-162.

[5] Motamed A, Bahia HU. J. Mater. Civ. Eng. 2011, 23(10), 14221432.

[6] Golalipour A, Bahia HU, Tabatabaee HA. J. Mater. Civ. Eng. 2017, 29(5), 04016295.

[7] Kataware AV, Singh D. Int. J. Pavement Res. Technol. 2015, 8(6), 410-418.

[8] Merusi F. Road Mater. Pavement Des. 2012, 13(S1), 321-345.

[9] Domingos MDI, Faxina AL. Int. J. Pavement Eng. 2015, 16(9), 771783.

[10] Elnasri M, Airey G, Thom N. Mech. Time-Depend. Mater. 2018, 1-21.

[11] Stempihar J, Gundla A, Underwood BS. J. Mater. Civ. Eng. 2018, 30(2), 04017283.

[12] Delgadillo R, Cho DW, Bahia H. Transp. Res. Rec. 2006, 1962, 3-11.

[13] D’Angelo JA. Road Mater. Pavement Des. 2009, 10, 61-80.

[14] Golalipour A. Modification of Multiple Stress Creep and Recovery Test Procedure and Usage in Specification. MSc Thesis, 2011.

[15] Wasage TLJ, Stastna J, Zanzotto L. Int. J. Pavement Eng. 2011, 12(6), 561-568.

[16] Saboo N, Kumar P. Constr. Build. Mater. 2015, 96, 632-640.

[17] Kennedy TW, Huber GA, Harrigan ET, Cominsky RJ, Hughes CS, Quintus HV, Moulthrop, JS. Superior Performing Asphalt Pavements (Superpave): The Product of the SHRP Asphalt Research Program, SHRP-A-410, Strategic Highway Research Program, National Research Council, 1994.

[18] Airey GD. Int. J. Pavement Eng. 2007, 5(3), 137-151.

[19] Woo WJ, Ofori-Abebresse E, Chowdhury A, Hilbrich J, Kraus Z, Martin AE, Glover CJ. Polymer Modified Asphalt Durability in Pavements. Final Report, FHWA/TX-07/0-4688-1, Texas Transportation Institute, Texas Department of Transportation, 2007.

[20] Santagata E, Baglieri O, Dalmazzo D, Tsantilis L. Mater. Struct. 2013, 46(10), 1673-1682.

[21] Cardone F, Ferrotti G, Frigio F, Canestrari F. Constr. Build. Mater. 2014, 71, 435-443.

[22] Kumar SA, Sarvanan U, Krishnan JM, Veeraragavan A. Int. J. Pavement Eng. 2014, 15(9), 767-785.

[23] Artamendi I, Allen B, Sabin P, Phillips P. Proceedings of the 6th Eurasphalt \& Eurobitume Congress, 2016.

[24] Mazumder M, Kim H, Lee S. Int. J. Pavement Eng. 2016, 9(2), 128-139.
[25] Saboo N, Kumar P. Adv. Civ. Eng. 2016, 2016.

[26] Lucena MCC, Soares SA, Soares JB. Mater. Res. 2004, 7(4), 529534.

[27] Fernandes MRS, Forte MMC, Leite LFM. Mater. Res. 2008, 11(3), 381-386.

[28] Jamshidi A, Hamzah MO, Aman MY. Mater. Res. 2012, 15(4), 628638.

[29] Kluttz RQ, Jellema E, Woldekidan MF, Huurman M. Proceedings of the 2013 Airfield and Highway Pavement Conference, 2013.

[30] Willis JR, Timm DH, Kluttz R. Transp. Res. Rec. 2016, 2575, 1-9.

[31] Chen JS, Wang TJ, Lee CT. Constr. Build. Mater. 2018, 171, 539545.

[32] Ahmedzade P. Constr. Build. Mater. 2013, 38, 285-291.

[33] Guo M, Tan Y. Int. J. Pavement Eng. 2019.

[34] Polacco G, Stastna J, Biondi D, Zanzotto L. Curr. Opin. Colloid Interface Sci. 2006, 11(4), 230-245.

[35] Kanabar N. Comparison of Ethylene Terpolymer, Styrene Butadiene, and Polyphosphoric Acid Type Modifiers for Asphalt Cement. PhD Dissertation, 2010.

[36] Singh SK, Kumar Y, Ravindranath SS. Polym. Degrad. Stab. 2018, 147, 64-75.

[37] Bulatovic VO, Rek V, Markovic KJ. J. Elastomers Plast. 2014, 46(5), 448-469.

[38] Yildirim Y. Constr. Build. Mater. 2017, 21(1), 66-72.

[39] Wang C, Wang H, Zhao L, Cao D. Constr. Build. Mater. 2017, 155 , 26-36.

[40] Huang W, Tang N. Constr. Build. Mater. 2015, 93, 514-524.

[41] Blazejowski K, Dolzycki B. Proceedings of the Geo-Hubei 2014 International Conference on Sustainable Civil Infrastructure, 2014.

[42] Wu S, Wen H, Chaney S, Littleton K, Muench S. J. Perform. Constr. Fac. 2017, 31(1), 04016074.

[43] Yang X, You Z. Constr. Build. Mater. 2015, 76, 380-387.

[44] Sybilski D. Transp. Res. Rec. 1996, 1535, 15-21.

[45] Wang C, Zhang J. Int. J. Eng. Technol. 2014, 6(1), 30-33.

[46] Adorjányi K, Füleki P. Cent. Eur. J. Eng. 2013, 3(3), 534-540.

[47] Hafeez I, Kamal MA. Arabian J. Sci. Eng. 2014, 39(8), 5971-5978.

[48] Domingos MDI, Faxina AL, Bernucci LLB. Constr. Build. Mater. 2017, 144, 207-213.

[49] Bastos JBS, Babadopulos LFAL, Soares JB. Constr. Build. Mater. 2017, 145, 20-27.

[50] DuBois E, Mehta Y, Nolan A. Constr. Build. Mater. 2014, 65, 184190.

[51] Zhang J, Walubita LF, Faruk ANM, Karki P, Simate GS. Constr. Build. Mater. 2015, 94, 218-227.

[52] Radhakrishnan V, Sri MR, Reddy KS. Constr. Build. Mater. 2018, 173, 298-307.

[53] Moura E. Estudo de Deformação Permanente em Trilha de Roda de Misturas Asfálticas em Pista e em Laboratório. PhD Dissertation, 2010. [in Portuguese] 